\title{
¿Cómo prevenir la caries dental?
}

\author{
Federico Morales Corona
}

\section{Resumen}

Este podcast tiene como objetivo brindar información importante y puntual acerca de qué son las caries, su origen y cómo se pueden prevenir.

Palabras clave: caries, salud dental, podcast, divulgación de la ciencia.

\section{How to Prevent Tooth Cavities?}

\section{Abstract}

The goal of this podcast is to give relevant and specific information about what tooth cavities are, their origin and the way we can prevent them.

Keywords: tooth cavities, dental health, podcast, science popularization. 
"¿Cómo prevenir la caries dental?" Federico Morales Corona

Vol. 22, Núm. 2, marzo-abril 2021

Revista Digital Universitaria

\section{Federico Morales Corona}

fmorales@enes.unam.mx

orcid.org/0000-0002-3441-1495

Facebook: Odontopediatría Corona

Médico Estomatólogo por la Universidad Autónoma de San Luis Potosí, con especialidad en Odontopediatría en el Departamento de Posgrados e Investigación de la Facultad de Odontología de la unAm. Experiencia laboral en la Secretaria de Salud como auxiliar de la Coordinación del Departamento de Salud Bucal de la Jurisdicción iv en San Luis Potosí y capacitador en la Encuesta Nacional de Caries y Fluorosis Dental 2010. Miembro del Comité organizador del Colegio Dental Potosino A. C. de 2007 - 2017.

Su tema de investigación son las pastas antibióticas en el tratamiento pulpar y ortopedia maxilar. Está adscrito a la Escuela Nacional de Estudios Superiores (ENES), Unidad León Guanajuato, de la unAM, de 2014 a la fecha. Imparte materias clínicas y teóricas de Odontología Preventiva y Comunitaria, y Odontopediatría en Pregrado y Posgrado. 
A través de mi experiencia como odontólogo, uno de los principales retos que he identificado ha sido la divulgación de la información. Sé sin duda que, comparado con las importantes enfermedades cubiertas por el esquema de vacunación, por ejemplo, la caries dental no parece tan importante. Es precisamente por razones como ésta, que las autoridades del país descuidan la importancia de la salud bucal. No es sino con el esfuerzo del gremio, como en el caso de la odontología, que temas de importancia como la caries dental se logran rescatar y se puede difundir información seria y consensada a la población en general, con el objetivo de reducir los problemas, en este caso, de la caries dental.

Por supuesto que este pequeño podcast es sólo una minúscula parte de toda esa información por difundir, pero, en él, quiero aplicar algo que les comento a los pacientes cuando toco el tema:

- Gran parte de la responsabilidad de la situación de la caries dental en México no es de los pacientes, sino de nosotros los odontólogos, que somos quienes contamos con la información puntual, pero que no la difundimos lo suficiente para provocar un impacto.

La información es una gran herramienta para la solución de los problemas, el contar con ella puede hacer la diferencia.

El desarrollo de este podcast me ha dejado como aprendizaje la motivación para utilizar las nuevas herramientas digitales en la divulgación de la información. Ésta ha sido una actividad que he ido incrementando con el paso del tiempo. Esta experiencia me deja en claro que, no importa lo pequeño que parezca, la aportación puede ser muy grande.

No puedo dejar de agradecer a la cuAIEED por la oportunidad de aprendizaje que brindan en las diferentes herramientas digitales, con buenas plataformas, y el desarrollo de nuevas habilidades académicas. Ejemplo de ello es el taller "Herramientas para la educación docente. De lo oral a lo digital", que sin su ayuda no hubiera sido posible lograr esta participación.

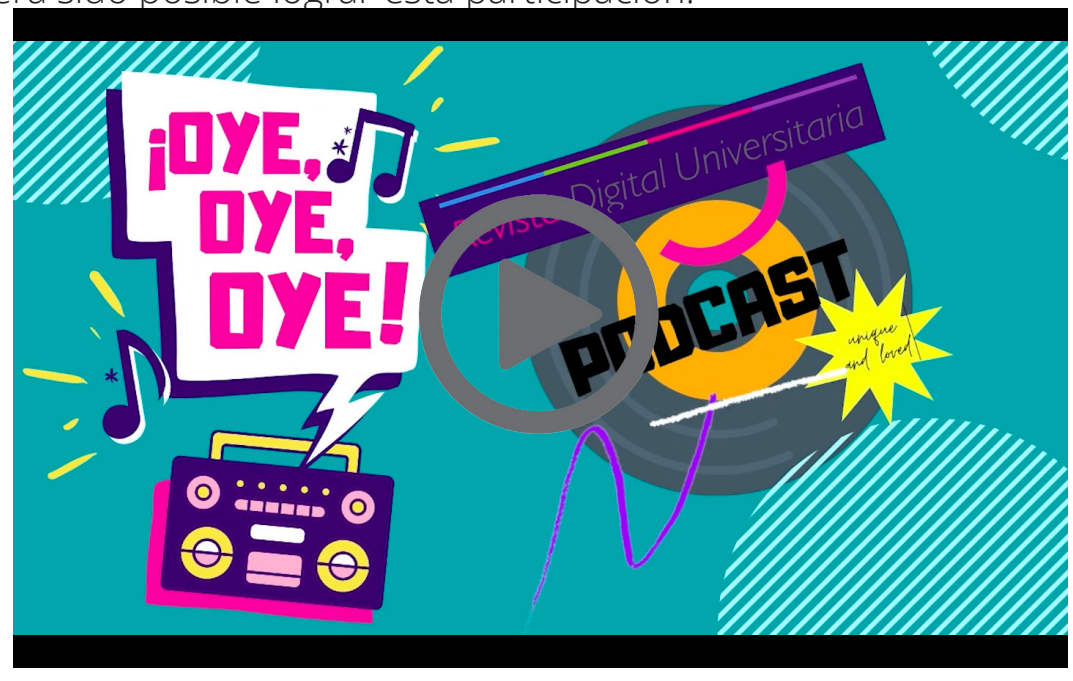




\section{Sitios de interés}

* Un Dentista En Youtube. (2006, 15 de septiembre). [canal]. YouTube. https://www. youtube.com/c/UnDentista/featured

\section{Cómo CITAR ESTE ARTículo}

* Morales Corona, Federico. (2021, marzo-abril). ¿Cómo prevenir la caries dental? Revista Digital Universitaria (RDU), 22(2). Dol: http://doi.org/10.22201/ cuaieed.16076079e.2021.22.2.12 